\title{
Perbaikan Teknis Sistem Pencatatan Persediaan Barang Berbasis Komputer bagi Pedagang Buku Pasar Palasari Kota Bandung Menghadapi Era Pasar Kompetitif
}

\author{
Zen Munawar $^{1^{*}}$, Mira Ismirani Fudsyi ${ }^{2}$, Dadad Zainal Musadad ${ }^{3}$ \\ ${ }^{1,3}$ Manajemen Informatika, Politeknik LP3I Bandung - J1. Pahlawan Non 59 Bandung \\ ${ }^{2}$ Akuntansi, Politeknik LP3I Bandung - Jl. Pahlawan Non 59 Bandung \\ *e-mail corresponding author : munawarzen@ gmail.com. No. HP 081802057736
}

\begin{abstract}
ABSTRAK
Pasar Buku Palasari kota Bandung adalah pindahan dari Pasar Buku Cikapundung pada tahun 1975 bertempat di atas pasar tradisional Palasari. Saat komsumen mencari buku yang spesifik judulnya seperti yang penulis dengan dari pengunjung mencari sebuah judul buku "Pembinaan Penghuni Lapas", banyak kios yang mengatakan tidak punya, padahal ini peluang untuk dilayani dengan cepat apabila tersedia aplikasi akuntansi persediaan barang yang pada tahap awal diterapkan terlebih dahulu untuk masing-masing kios buku yang sudah siap dengan pembangungan "Perpetual Inventory Card secara Elektronik/Komputer" kemudian untuk tahap penelitian selanjutnya dibangun katalog buku yang mencakup seluruh kios buku untuk buku yang dimiliki oleh semua kios-buku. Agar konsumen ini dapat terlayani dengan baik, maka perlu adanya katalog buku terpadu yang menampung semua judul buku yang ada di Pasar Buku Palasari, yang pada tahap awal dibangun untuk kios buku yang sudah siap dengan model pencatatan persediaan barang model Perpetual Inventory Card. Metode untuk mengatasi permasalahan mitra dilakukan dengan cara penyuluhan, pelatihan dan pendampingan penggunaan aplikasi. Hasil karya berupa Perpetual Inventory Card dengan model relasi basis data yang berguna untuk terhubungnya pembeli dalam kegiatan membeli buku dengan pedagang kios buku pada Pasar Palasari yang digabung dengan aplikasi berbasis web, maka saatnya untuk publikasi Katalog Buku kios-buku Pasar Palasari secara on-line, sehingga peluang untuk mendapatkan pasar yang lebih luas akan terlayani untuk semua kios baik yang memiliki modal yang cukup maupun yang kurang, ibaratnya kosumen masuk ke sebuah toko buku besar yang isinya ratusan kios buku. Dan ini dapat kita realisasikan apabila mereka dibantu dengan teknologi informasi.
\end{abstract}

Kata kunci : sistem pencatatan; persediaan barang; perpetual inventory; teknologi informasi

\section{ABSTRACT}

The Palasari Book Market in the city of Bandung was moved from the Cikapundung Book Market in 1975 located above the Palasari traditional market. When consumers look for books with specific titles such as those of writers with visitors looking for a book entitled "Guidance of Lapas Residents", many stalls say they do not have, even though this is an opportunity to be served quickly if there is an accounting application for inventory which is applied first. for each book kiosk that is ready with the "Electronic / Computer Perpetual Inventory Card" development, then for the next stage of the research, a book catalog will be built which includes all the book stalls for

Cara Mengutip : Munawar, Z., Fudsyi, M. I., Musadad, D. Z. (2020). Perbaikan Teknis Sistem Pencatatan Persediaan Barang Berbasis Komputer bagi Pedagang Buku Pasar Palasari Kota Bandung Menghadapi Era Pasar Kompetitif. JAST: Jurnal Aplikasi Sains dan Teknologi, 4 (1), 52-60. doi:http://dx.doi.org/10.33366/jast.v4i1.1587

\section{c) (i) (2)}

Content from this work may be used under the terms of the Creative Commons AttributionShareAlike 4.0 International License. Any further distribution of this work must maintain attribution to the author(s) and the title of the work, journal citation and DOI. 
books owned by all book stalls. So that these consumers can be served well, it is necessary to have an integrated book catalog that accommodates all book titles in the Palasari Book Market, which in the early stages were built for book kiosks that were ready with the inventory recording model of the Perpetual Inventory Card model. The method for overcoming partner problems is done by counseling, training and assisting in the use of the application. The work in the form of Perpetual Inventory Card with a database relationship model that is useful for connecting buyers in the activity of buying books with bookstore sellers in Palasari Market combined with a web-based application, then it's time to publish the Book Catalog of Palasari Market stalls on-line, so that the opportunity to get a broader market will be served for all stalls both with sufficient and less capital, like a customer entering a large bookstore with hundreds of book stalls. And this we can realize if they are assisted with information technology.

Keywords : recording system; inventory; perpetual inventory; information technology

\section{PENDAHULUAN}

Kompetisi global yang disertai dengan perkembangan dan kemajuan pesat di bidang industri dan teknologi informasi menyebabkan perubahan dan bergejolak di berbagai aspek dan bidang kehidupan manusia. Salah satu produk teknologi informasi adalah $e$-book, video, power point. Kondisi ini membuat usaha kecil dan menengah seperti kios-kios buku di lingkungan Pasar Buku Palasari berada dalam perangkap kompetisi yang bergejolak. Seperti yang kita ketahui bahwa Usaha Mikro, Kecil dan Menengah (UMKM) kita belum siap menghadapi persaingan ini, bahkan apabila kita biarkan, relakah kita melihat satu persatu kios-kios buku di Pasar Buku tutup dan gulung tikar, dan yang pada saat ini sedang berlangsung. Kewirausahaan sosial adalah proses penciptaan sosial dengan menggabungkan sumber daya yang terfokus untuk mengejar dan mencari kesempatan [1]. Maka kita sebagai masyarakat intelektual yang memiliki kemampuan untuk membantu diwajibkan terhadap kita untuk membantu mereka yang usahanya pada saat ini sedang mati suri seperti yang diungkapkan oleh Wakil Ketua Pengurus Persatuan Pedagang dan
Tik Buku Pasar Palasari Bandung, PP Butindo Bapak Benny Arnanda. Pada saat ini sudah ada beberapa kios-buku yang sudah beralih kepemilikan, karena pemilik lama sudah tidak tahan dengan kondisi usaha penjualan buku seperti ini. Wirausaha adalah sebuah pemikiran untuk mewujudkan apayang diinginkan oleh diri kita tanpa ada sebuah batasan yang dibatasi oleh orang lain dan dapat mengembangkannya ke tahapan yang lebih tinggi [2].

Persaingan yang bersifat global dan tajam di bidang industri penerbitan buku menyebabkan terjadinya penurunan pendapatan yang diperoleh pelaku usaha kios-kios buku Pasar Palasari Bandung, terlebih dengan lebih mudahnya mengunduh refersensi dari internet dan kebijakan pemerintah atas penyediaan buku-buku pelajaran sekolah dengan cara mengunduhnya. Pendapatan adalah arus masuk bruto dari manfaat ekonomi yang timbul dari aktivitas normal entitas selama suatu periode, jika arus masuk tersebut mengakibatkan kenaikan ekuitas yang tidak berasal dari kontribusi penanam modal [3].

Buku-buku yang terlanjur dibeli putus oleh pedagang kios banyak yang 
cenderung menganggur di rak buku, seperti buku pelajaran sekolah dikarenakan adanya kebijakan paket Bantuan Operasional Sekolah (BOS). Buku-buku lain yang terkait dengan teknologi, komputer, buku lokal, bukubuku peraturan pemerintah yang kerap berubah menjadi pajangan memenuhi rak pajangan buku. Hanya jenis buku tertentu yang peminatnya terbatas yang masih relatif dapat dijual seperti buku sejarah, buku biograhi, novel, hukum, sastra, kamus, terjemahan text book. Hal ini menjadi sepenuhnya beban pemilik, karena sistem penjualan dengan jual putus dengan penerbit, bukan konsinyasi. Pedagang kios buku harus mempunyai strategi dalam meningkatkan penjualan buku. Strategi memungkinkan organisasi untuk mendapatkan keunggulan kompetitif dari tiga dasar kepemimpinan harga, diferensiasi, dan fokus [4].

Kondisi penurunan penjualan secara kasat mata ini diperparah dengan tidak siapnya para pemilik kios yang kebanyakan sekaligus sebagai pelaku penjual dengan informasi pendukung atas status persediaan barang dagangnya. Kalaupun ada data tentang persediaan barang dagang atas barang masuk yang sudah ada di komputer, namun tidak up to date, hal ini karena pemilik / penjual malas untuk menulis nota penjualan sebagai dokumen pendukung pengurang dalam pencatatan barang persediaan. Pencatatan transaksi persediaan barang dagangan dengan metode ini tidak langsung berkaitan dengan barang dagang yang bersangkutan [5].

Stock opname pun jarang dilakukan dan tidak dilakukan secara periodik, sehingga pada akhirnya sulit untuk mengetahui informasi tentang laporan keuangan yang reliable. Penggunaan metode periodik mengharuskan adanya perhitungan barang yang masih ada pada tanggal penyusunan laporan keuangan [6]. Apalagi didalam persediaan barang yang ada, terdapat didalamnya barang-barang yang termasuk barang yang lambat bergerak ( slow moving ), tidak sesuai untuk dijual (obsolensence) yang tentu saja berpengaruh kepada nilai persediaan barang tetapi secara pencatatannya tidak disadari oleh pemilik kios. Bagaimanapun juga pedagang kios buku pasar palasari harus mendapatkan keuntungan / marjin dari penjualan buku. Marjin laba kotor yang memperlihatkan hubungan antara penjualan dan beban pokok penjualan, mengukur kemampuan perusahaan untuk mengendalikan biaya persediaan atau biaya operasi barang maupun untuk meneruskan kenaikan harga lewat penjualan kepada pelanggan [7]. Pengembalian atas Total Aset, merupakan pengukuran kemampuan perusahaan secara keseluruhan di dalam menghasilkan keuntungan/laba dengan memanfaatkan aktiva yang tersedia dalam perusahaan [8].

Keadaan ini memaksa manajemen UMKM kios buku Palasari mencari berbagai strategi baru yang menjadikan usaha perdagangan buku mereka mampu bertahan dan berkembang dalam persaingan tingkat nasional bahkan tingkat dunia. Hanya UMKM kios buku yang memiliki keunggulan pada tingkat nasional maupun dunialah yang mampu bertahan dan berkembang, unggul dalam memenuhi dan melayani kebutuhan konsumen, mampu menghasilkan layanan (out put) yang bermutu, dan cost effective [9]. 


\section{METODE KEGIATAN}

Untuk dapat melaksanakan kegiatan pengabdian pada masyarakat maka dilakukan tahan persiapan dan pelaksanaan, dimana tahap ini bertujuan untuk mengetahui menganalisa dan membangun solusi untuk pengembangan usaha Kios Pedagang Buku Pasar Palasari agar terjadi peningkatan keunggulan kompetitif kios buku, sehingga para pedagang Kios Buku Pasar Palasari lebih berkembang dan terjaga kesinambungan usahanya. PKM ini dilaksanakan pada kios buku Pasar Palasari di Bandung Jawa Barat, dengan waktu pengabdian pada masyarakat selama 9 bulan mulai dari bulan April 2019 sampai dengan bulan Desember 2019.

Pelatihan, pada tahap pelatihan ini dilaksanakan di tempat yang dekat dengan pasar buku Palasari Bandung dan disesuaikan dengan kondisi mitra supaya lebih mudah terjangkau oleh peserta yaitu di terletak di Jl. Palasari kota Bandung. Dalam metode pelatihan menggunakan metode praktis sesuai dengan masalah yang dihadapi dan kebutuhan mitra. Pelatihan yang diberikan meliputi : pelatihan proses akuntansi, siklus akuntansi, arus proses akuntansi, laporan keuangan, contoh kasus, dan pengelolaan persediaan. Pelatihan atau training adalah merupakan suatu metode yang diberikan dalam rangka memberikan ilmu pengetahuan dan hal-hal tertentu yang dibawakan oleh seorang trainer [2]. a) Pelatihan bagian 1 (satu) ; Pelatihan kreativitas dan inovasi ditujukan agar mitra memiliki daya kreativitas dan daya inovasi. Dalam pelatihan kreativitas mitra diberikan gambaran mengenai cara-cara menciptakan gagasan-gagasan baru, pelatihan menemukan cara baru dalam menyikapi masalah dan usaha kios buku serta memanfaatkan peluang usaha dalam pengembangan pelayanan terhadap pembeli buku dan calon pembeli buku. Sedangkan dalam pelatihan inovasi mitra dilatih untuk dapat meningkat keunggulan bersaing dalam upaya meningkatkan dan mempertahankan kesinambungan usaha bisnis buku pedagang kios buku pasar Palasari Bandung. b) Pelatihan bagian 2 (dua) : Pelatihan tentang pentingnya pencatatan persediaan yang mencakup pelatihan proses akuntansi, siklus akuntansi, arus proses akuntansi, dan laporan keuangan. Pelatihan sumber daya manusia (sdm) dan pelatihan akuntansi seperti pembuatan laporan keuangan dan pelatihan manajemen keuangan.

Simulasi Ipteks, untuk memudahkan kegiatan sehari-hari pada pedagang kios buku pasar Palasari Kota Bandung maka akan dibangun basis data untuk aplikasi akuntansi persediaan barang yang pada tahap awal diterapkan terlebih dahulu untuk masing-masing kios buku yang sudah siap dengan pembangunan "Perpetual Inventory Card" secara Elektronik / Komputer.

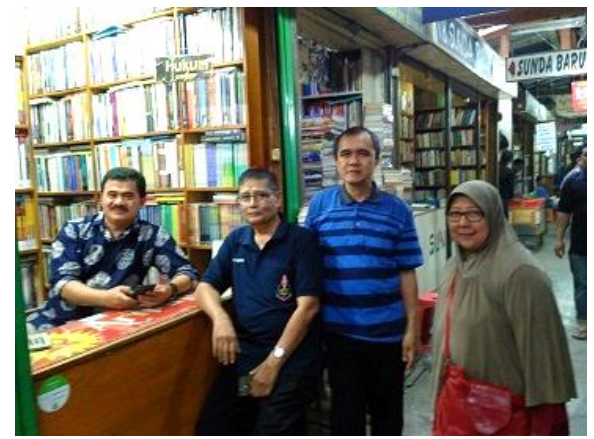

Gambar 1. Pertemuan Ketua dan Anggota Tim PKM dengan Ketua Asosiasi Pedagang Buku Pasar Palasari Bapak Beni Arnanda. 
Komunikasi dilakukan oleh Ketua dan Anggota Tim PKM dengan mendatangi secara langsung ke Pasar Palasari dan menemui Ketua Asosiasi Pedagang Buku Pasar Palasari Bapak Beni Arnanda, seperti terlihat pada gambar 1.

Pada kesempatan tersebut disampaikan maksud dan tujuan kegiatan pengabdian kepada masyarakat.

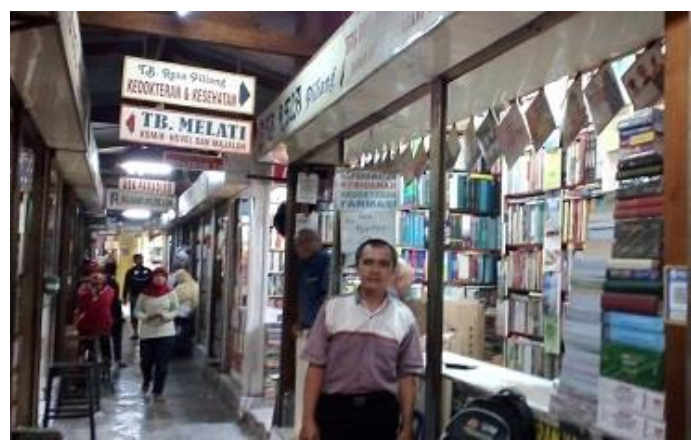

Gambar 2. Suasana di dalam Lorong Pasar Buku Palasari

Pedagang kios buku pasar Palasari menempati tempat yang berbeda-beda, ada yang di depan pinggir jalan dan ada juga yang menempati bagian tengah atau lorong pasar buku Palasari, seperti terlihat pada gambar 2, suasana di dalam lorong pasar buku Palasari. Pedagang menempati area kiri dan kanan lorong.

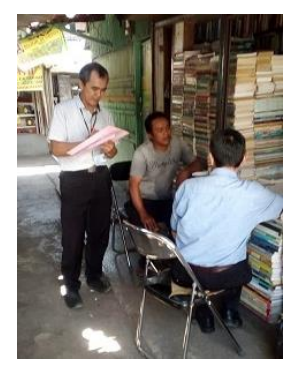

Gambar 3. Pengambilan Data pada Pedagang Pasar Buku Palasari

Pada gambar 3, tim dalam melaksanakan kegiatan pengabdian masyarakat melakukan pengambilan data kepada masing-masing pedagang di pasar buku Palasari.

\section{KARYA UTAMA}

Dalam hal ini tim membuat model relasi basis data yang berguna untuk terhubungnya pembeli dalam kegiatan membeli buku dengan pedagang kios buku pada Pasar Palasari, sedangkan bagi pedagang buku dapat saling membantu dalam memasarkan buku yang tidak tersedia di tempat kios bukunya. Selanjutnya dibuat aplikasi sistem pencatatan persediaan dengan metode perpetual. Pasar Palasari Bandung baik dari aspek permodalan, trend usaha, dan daya saing usaha untuk mendukung kesinambungan usaha menggunakan metoda analisis lingkungan. Model database aplikasi akuntansi persediaan barang dapat membantu meningkatkan pelayanan konsumen dan calon konsumen sekaligus alat pengendalian persediaan barang dagangan.

Tujuan dari perancangan basis data adalah melayani kebutuhan penyimpanan data barang dagangan kios buku. Sistem akan menyimpan catatan semua transaksi yang dilakukan selama bisnis berjalan dan akan memberikan referensi di masa mendatang. Sistem akan dirancang dan dipersiapkan untuk implementasi, mempelajari lingkungan operasional dan kebutuhan pengusahan. Fokus pekerjaannya adalah mengidenti-fikasi kebutuhan pengguna dan pengembangan desain basis data logis, sistem independen yang akan memenuhi kebutuhan pengguna. Proses desain database dibagi menjadi beberapa tahapan desain yang berbeda sesuai dengan proses desain yang diikuti. Model ini akan fokus pada desain database logis. Juga akan diperkenalkan Fase desain basis data fisik. 
Identifikasi dan asosiasi atribut untuk Entitas. Dalam langkah proses desain ini, entitas yang ditemukan pada langkah sebelumnya ditugaskan dengan atribut. Atribut yang mungkin dari analisis dokumen perusahaan dan wawancara pengguna didokumentasikan dalam langkah ini. Nama tebal adalah entitas dan mengikuti atributnya.

\section{Admin}

Kd_admin, Nama_admin, Email, Password, Gambar

\section{Barang}

Kd_barang, Nama_barang, Harga_jual, Harga_beli, Stok

\section{Barang_sementara}

ID_barangp, Kd_pembelian, Nama_barangp, Harga_barangp, Item, Total

\section{Barang_pembelian}

Kd_barang_beli, Kd_pembelian, Nama_barang_beli, Harga_beli, Item, Total

\section{D_pembelian}

ID_pembelian, Kd_pembelian, Kd_barang_beli, Jumlah, Subtotal

\section{D_penjualan}

ID_penjualan, Kd_penjualan, Kd_barang, Jumlah, Subtotal

\section{Pembelian}

Kd_pembelian, Tanggal_pembelian, Kd_admin, Kd_supplier, Total_pembelian

\section{Penjualan}

Kd_penjualan, Tanggal_penjualan, Kd_admin, Dibayar, Total_penjualan

\section{Penjualan_sementara}

ID_penjualan_sementara, Kd_penjualan, Kd_barang, Nama_barang, Harga, Item, Total

\section{Perusahan}

Kd_perusahaan, Nama_perusahaan, Alamat, Pemilik_perusahaan, Kota

\section{Supplier}

Kd_supplier, Nama_supplier, Alamat

Atribut-atribut yang secara unik dapat mengidentifikasi seluruh entitas adalah kunci kandidat. Salah satu dari atribut ini adalah kunci primer dan kunci lainnya adalah kunci alternatif.

Berikutnya akan ditampilkan asosiasi antara entitas kunci primer dengan kunci alternatif

Tabel 1. Asosiasi entitas dengan kunci kandidat, kunci primer dan kunci alternatif.

\begin{tabular}{|c|c|c|c|}
\hline Entity & $\begin{array}{l}\text { Candidate } \\
\text { keys }\end{array}$ & $\begin{array}{l}\text { Primary } \\
\text { key }\end{array}$ & $\begin{array}{l}\text { Alternate } \\
\text { keys }\end{array}$ \\
\hline admin & $\begin{array}{l}\text { kd_admin, } \\
\text { nama, email }\end{array}$ & kd_admin & nama, email \\
\hline barang & $\begin{array}{l}\text { kd_barang, } \\
\text { nama_baran } \\
\text { g }\end{array}$ & $\begin{array}{l}\text { kd_baran } \\
\mathrm{g}\end{array}$ & $\begin{array}{l}\text { nama_baran } \\
\mathrm{g}\end{array}$ \\
\hline $\begin{array}{l}\text { barang_sement } \\
\text { ara }\end{array}$ & $\begin{array}{l}\text { id_barangp, } \\
\text { nama_batan } \\
\text { gp }\end{array}$ & $\begin{array}{l}\text { id_barang } \\
\text { p }\end{array}$ & $\begin{array}{l}\text { nama_baran } \\
\text { gp }\end{array}$ \\
\hline
\end{tabular}

Hubungan antara entitas dan atribut diturunkan selama langkah ini. Komposisi masing-masing hubungan dijelaskan menggunakan Database Definition Language (DDL). Nama setiap relasi ditentukan menggunakan DDL diikuti oleh daftar atribut yang dilampirkan dalam tanda kurung. Kunci primer (pk), kunci alternatif (ak), kunci sekunder (sk) dan kunci asing (fk) dari relasi diidentifikasi. Hubungan antar tabel ditunjukkan pada gambar 4 di bawah ini : 


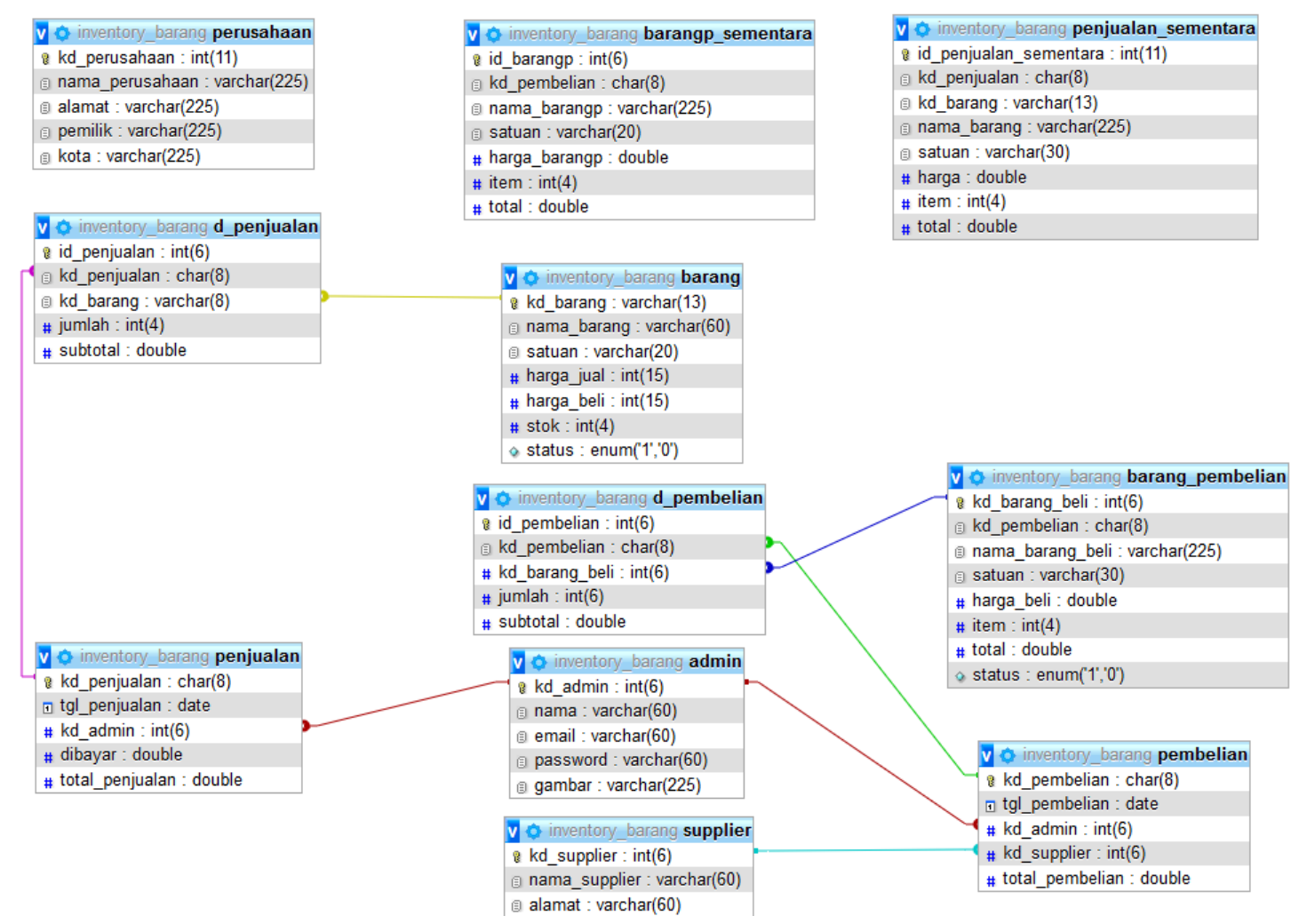

Gambar 4. Hubungan antar tabel

Implementasi dari aplikasi pencatatan persediaan barang, tersedia pada Url : http://pkmpalasari.com dan ditampilkan dalam beberapa gambar agar dapat bisa dilihat kegunaan dari aplikasi tersebut, adapun rincian dari menu dan sub menu aplikasi sebagai berikut :

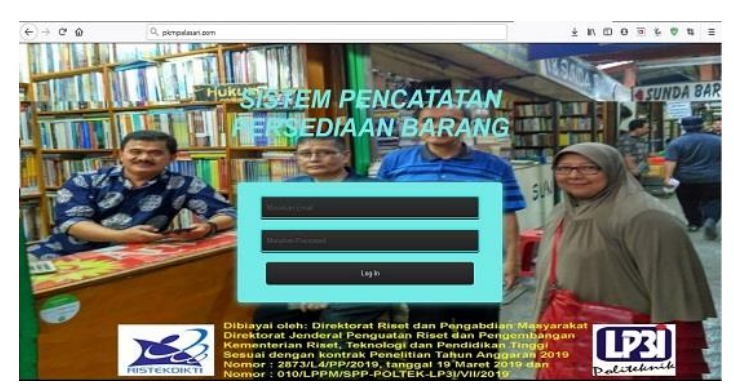

Gambar 5. Halaman Login

Pada halaman login, pemilik sebagai admin akan mengisikan data email dan password, selanjutnya akan muncul menu dashboard.

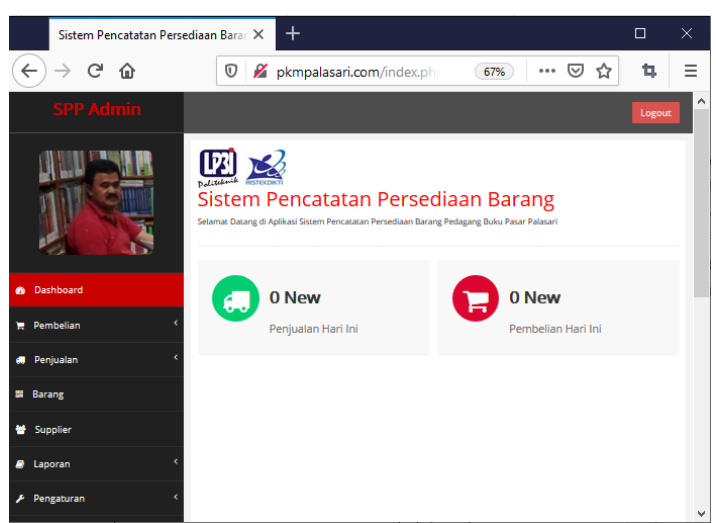

Gambar 6. Halaman Dashboard

Pada halaman dashboard berisi menu pembelian, penjualan, barang, supplier, laporan dan pengaturan.

\section{ULASAN KARYA}

Basis data Perpetual Inventory yang sudah siap baik hardware, software maupun brainware dapat meningkatkan peningkatan pelayanan kepada pembeli 
dan calon pembeli dalam penyediaan katalog buku. Selanjutnya dengan adanya program aplikasi akuntansi persediaan barang, dapat membantu meningkatkan pelayanan konsumen dan calon konsumen sekaligus dapat menjadi alat pengendalian persediaan barang dagangan berupa buku.

\section{DAMPAK DAN MANFAAT KEGIATAN}

Kegiatan ini memberikan manfaat kepada pihak mitra berupa dibangunnya aplikasi sistem pencatatan persediaan barang berbasis website dengan alamat Url. http://pkmpalasari.com, dibuat dengan bahasa pemrograman PHP dan database MySQL. Adanya aplikasi berbasis website akan memudahkan bagi pengguna untuk menjalankan aplikasi ini karena cukup dijalan di aplikasi browser yang tersedia di komputer [10].

Berikut tabel perbandingan antara kondisi mitra sebelum dilakukan program kemitraan masyarakat dengan kondisi mitra setelah dilakukan program kemitraan masyarakat.

Tabel 2. Perbandingan Sebelum dan Sesudah Kegiatan Program Kemitraan Masyarakat

\begin{tabular}{|c|c|}
\hline $\begin{array}{l}\text { Sebelum Program } \\
\text { Kemitraan Masyarakat }\end{array}$ & $\begin{array}{l}\text { Sesudah Program } \\
\text { Kemitraan Masyarakat }\end{array}$ \\
\hline $\begin{array}{ll}\text { Mitra belum } & \text { memahami } \\
\text { tentang } & \text { pentingnya } \\
\text { pencatatan } & \text { persediaan } \\
\text { barang } & \end{array}$ & $\begin{array}{l}\text { Diberikan } \begin{array}{r}\text { pelatihan } \\
\text { bang }\end{array} \\
\text { pengelolaan persediaan, } \\
\text { proses akuntansi, siklus } \\
\text { akuntansi, arus proses } \\
\text { akuntansi, laporan } \\
\text { keuangan, contoh kasus, } \\
\text { dan pengelolaan } \\
\text { persediaan. }\end{array}$ \\
\hline $\begin{array}{l}\text { Mitra belum memiliki } \\
\text { aplikasi } \\
\text { melakukan pencatatan } \\
\text { persediaan barang secara } \\
\text { online. }\end{array}$ & $\begin{array}{lr}\text { Dibuatnya } & \text { aplikasi } \\
\text { sistem } & \text { pencatatan } \\
\text { persediaan } & \text { barang } \\
\text { berbasis } & \text { web yang } \\
\text { membantu } & \text { pihak mitra } \\
\text { dalam } & \text { melakukan } \\
\text { pencatatan } & \text { persediaan } \\
\text { barang ecara online }\end{array}$ \\
\hline $\begin{array}{l}\text { Mitra belum mengetahui } \\
\text { bagaimana }\end{array}$ & $\begin{array}{l}\text { Dilakukan } \\
\text { pendampingan }\end{array}$ \\
\hline
\end{tabular}

\begin{tabular}{lrl}
\hline penggunaan aplikasi & dengan pihak mitra \\
sistem pencatatan & mengenai penggunaan \\
persediaan barang yang & aplikasi yang dibuat \\
dibuat &
\end{tabular}

Aplikasi sistem pencatatan persediaan barang telah dilakukan serah terima dari Ketua Tim PKM dengan Bapak Beni Arnanda selaku Ketua PP Butindo (Asosiasi Pedagang Kios Buku Pasar Palasari Bandung) yang juga pemilik toko buku Arnanda .

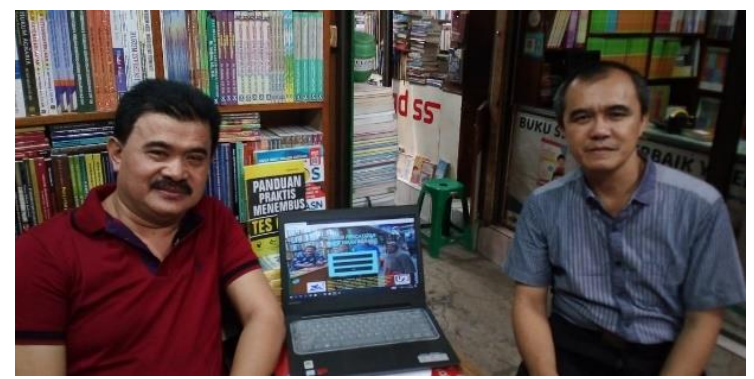

Gambar 7. Serah Terima Aplikasi

\section{KESIMPULAN}

Perbaikan Teknis Sistem Pencatatan Persediaan Barang Berbasis Komputer Bagi Pedagang Buku Pasar Palasari Kota Bandung Menghadapi Era Pasar Kompetitif sebagian besar kegiatan telah dijalankan dengan baik berkat peran serta aktif dari tim baik dari ketua maupun anggota tim pengabdian didukung oleh komunikasi serta kontribusi dari ketua dan perwakilan kiuos pedagang buku Pasar Palasari Bandung.

Semua kegiatan yang direncanakan berjalan sesuai dengan yang diharapkan dan harapannya dapat memberikan manfaat dalam kelancaran usaha pedagang kios buku khususnya dalam pencatatan persediaan.

Telah dilakukan perancangan basis data dan implementasi aplikasi sistem pencatatan persediaan barang. 


\section{PENGHARGAAN}

Dalam kesempatan ini tim PKM menyampaikan ucapan terimakasih kepada Kemenristekdikti yang telah memberikan dana sehingga terselenggaranya kegiatan PKM serta Lembaga Penelitian dan Pengabdian Pada Masyarakat Politeknik LP3I Bandung yang telah membantu tim dalam melaksanakan kegiatan dari awal sampai akhir kegiatan,

Ucapan yang sama juga disampaikan kepada Mitra Kerja ketua asosiasi pedagang kios buku Pasar Palasari Bapak Beni Arnanda serta perwakilan pengurus asosiasi yang telah bekerjasama dan membantu melakukan komunikasi kepada pedagang kios buku Pasar Palasari Bandung. Pedagang kios buku pasar Palasari yang telah bersedia membantu memberikan data-data yang diperlukan.

\section{DAFTAR PUSTAKA}

[1] W. Dhewanto, Intrapreneurship, Kewirausahaaan Korporasi. Bandung: Rekayasa Sains, 2013.

[2] S. Gendro, Panduan Bisnis Lengkap. Jakarta: Sinergi Media, 2010.

[3] D. E. Kieso, Akuntansi Intermediate, Jilid 1. Yogyakarta: Erlangga, 2007.

[4] M. E. Porter, Competitive Strategy. New York: The Free Press, 1985.

[5] N. M. Hamizar, Intermediate Accounting. Jakarta: CV Fajar, 2009.

[6] Z. Baridwan, Intermediate Accounting, 8th ed. Yogyakarta:
BPFE UGM, 2008.

[7] F. Irham, Kewirausahaan Teori, Kasus dan Solusi. Bandung: Alfabeta, 2014.

[8] P. Rufaidah, Manajemen Strategik. Bandung: Humaniora, 2012.

[9] Srimindarti, Cecilia, and M. K. Indarti, "Value Chain Analysis: Pengelolaan

Aktivitas untukMenciptakan Keunggulan Komptetitif," Fokus Ekon., vol. 2, pp. 1-7, 2003.

[10] M. Susilo, "Rancang Bangun Website Toko Online Menggunakan Metode Waterfall," InfoTekJar (Jurnal Nas. Inform. dan Teknol. Jaringan), vol. 2, no. 2, pp. 98-105, 2018. 